ARTICLE

Check for updates

https://doi.org/10.1057/s41599-020-0426-3

\title{
Monstering: a transdisciplinary method for an unstable world
}

\author{
Rachel Armstrong (iD) ${ }^{1 \times}$, Rolf Hughes (i) ${ }^{1} \&$ Simone Ferracina (iD ${ }^{2}$
}

\begin{abstract}
This paper outlines the transdisciplinary practice of monstering, a toolset used by the Experimental Architecture Group (EAG) to engage with a world in constant flux. The chapter describes recent Experimental Architecture projects that draw attention to the need for radical change at a time of ecocide. Our 'monstering' perspectives draw inspiration from the countless forms of cooperation and acts of generosity that underpin healthy ecological systems. Throughout the text, a range of different voices, materials, media and practices are brought together to synthesise the potentials of monstering. Monstering generates qualitatively new encounters in the choreography of space and its inhabitation. It challenges normative protocols and existing practices by embodying the unknown and uncontrollable aspects of the world. Through monstering, we embrace our innate zoephilia (Braidotti, 2006, p. 41), increasing our capacity to respond to an ever-changing reality and finding new ways of diplomacy to better communicate and acknowledge the contributions of non-human agents to our reality. EAG's monstering experiments seek to bring designed change to functionality (Haraway, 2015) through re-empowerment, re-connection and re-enchantment with an ecologically stressed world. The paper details monstering performances and installations as prototypes that draw attention to established preferences, conventions, and habits, celebrating diversity, difference and paradoxical encounters.
\end{abstract}

\footnotetext{
${ }^{1}$ School of Architecture, Planning \& Landscape, Newcastle University, Newcastle, UK. ${ }^{2}$ Edinburgh School of Architecture and Landscape Architecture, University of Edinburgh, Edinburgh, Scotland. ${ }^{凶}$ email: rachel.armstrong3@ncl.ac.uk
} 


\section{Introduction}

$\mathrm{t}$ the beginning of biogenesis was Paradoxa: selfcontradictory beings and agents of $z o \ddot{e}$ that embodied the unscripted character of life (Braidotti, 2006). In their natural state they sought no material, existential or functional principle. Nor did they seek justification of any kind. Left to their own devices, they produced a plethora of beings that sprang from the rocks, the sea and belly of the Cambrian Explosion. All bodies, parts and materials were perfectly formed and, following Mary Douglas' dictum, in their place (Douglas, 2008). Together, they produced the rich diversity of the natural world. By the eighteenth century, they were understood as a book that God had authored.

In the belief that he was God's chosen instrument, Carl Linnaeus set out to decode the glorious plan of Creation, revealing its laws through the 'economy of nature' - the way the divine organised His own household. Assuming that a rationalist, organising principle was at the heart of the natural world, he cast its perfect administration as a system that left nothing wanting or superfluous. Since everything had its proper place, mankind's duty was to examine and make use of its riches. In the role of accountant, Linnaeus set out to scrutinise God's book, classify His creations, establish their place in His system, and thereby reveal the orderliness of His creation.

Publishing the first edition of his Systema Naturae in 1735, Linnaeus described three kingdoms of nature: stones (or minerals), plants, and animals. By the tenth edition, in 1758, he had categorised around 4400 animal species, marking the start of zoological nomenclature, finally publishing twelve versions of the treatise. Each item was assigned a binomial name, but for all his collecting and measuring, one category vexed him-Paradoxa. Wrestling with their identity for the first five volumes of his divine book, he finally denounced Hydra, Rana-Piscis, Monoceros, Pelecanus, Satyr, Borometz, Phoenix, Bernicla, Draco, Automa Mortis as fabulous, mistaken and fraudulent. Like angels, Paradoxa were beyond the Creation of God (Sowerby, 2016, p. 19).

Paradoxa defy formal rationalisation or categorisation, and refuse to submit to notions of fitness, suitability, or utility of purpose. They are the source of monsters and a challenge to the natural state of beings. As joyous expressions of vibrant materiality, they are always already entangled with the geostory of the earth.

The scientific gaze has observed, measured, sampled and probed the conundrums of complex environments, yet has neglected the transformative space of "speculative" research - where there are no guarantees, only the exploration of limits. Space solicits narrative and architectonic monsters, but we have failed to articulate it as such, perhaps drawn to more domestic (or colonising) visions due to our fear of the unknown. Devised encounters with re-enlivened spaces, matter, and experiences can be described as monstering. The Experimental Architecture Group invokes the unknown and uncontrollable aspects of the world in an age of ecocide, generating qualitatively new encounters in the choreography of space and in the way space can be inhabited. Such research opens a space of radical transformation, a theatre of becoming, full of magic and enchantment. It subverts the tools of assessment applied to other research and demands new approaches. Traditional sites of architectural engagement are now joined by other spaces that nurture different kinds of narratives, encounters, expressions, bodies and new forms of existence. Recognising the innate 'weirding' within the material realm that is capable of invoking uncanny, supernatural or unearthly encounters, monstering explores how to increase our engagement with 'other' kinds of bodies by celebrating diversity, difference and paradox (Armstrong, 2019, p. 61-62), and by erasing taxonomy. Against the soothing consolations of coherence and causal rationality, we might yoke together disparate worlds to summon them forth - the fragile Paradoxa, the beings that do not conform. A fragile Paradox is an embodiment of experimentation where certainties have been torn apart and stitched together in new, provisional assemblages. Exploring the strange vitality of their own being, each Paradox enlivens our world, its innate monstering affecting the matter in which we are immersed and changing our understanding of what is possible. Here, monstering (always a verb, never a noun) evokes and prompts the beginning of a re-animated biosphere. A series of monstering invocations to initiate transdisciplinary research was performed between 2016 and 2019 by the Experimental Architecture Group. Collectively, these experiments exemplify our embrace of diverse materials, media, methods, collaborative partners and performative practices while retaining aesthetic and epistemological coherence by integrating each element through design and dramaturgy.

\section{The Temptations of the Nonlinear Ladder}

The Temptations of the Nonlinear Ladder (Palais de Tokyo, Paris, April 2016) explored the transition from one kind of embodied existence to another, invoking the shape-shifting nature of monsters and the uncertainty of our survival between two planes of existence. Core themes were:

- Non-linear ladder; embodying the transition from one set of existence conditions to another-such as from the water to the air, where unstable bodies, their interrelationships and space produce their own routes of access.

- Transitioning; in moments of transition, something strange happens to the idea of a body. The circus performers surrender their expectations of their embodied knowledge and training, their relationship to control and mastery-the horizons of their own physical parameters.

- Ascension; at the limits of existence, when things become undetermined, the artists are no longer embodied agencies, but excitable fields that shape the behaviour of matter far beyond the immediate spaces that are recognisably 'human'.

The experiment took the form of a series of public performances during the 2016 Do Disturb! festival, at the Palais de Tokyo, Paris, 8-10 April 2016. These ran three times a day over the course of the event. A circular, 4 metre diameter black mirror with a 4 centimetre-deep pool of water was centrally installed in the temple space of the main building. Above this, there was a circular 1.2 metre diameter polished aluminium platform tethered to a pulley and attached to a floor anchoring that could bear a central rigging load of around 600 kilogrammes. The performance space was lit from two aerial trusses, while cold light was available from the ground. Behind the central space, two television monitor screens displayed dynamic droplet videos in a continuous loop over the course of the event. Three fish bowls containing medaka fish, the only vertebrates to have bred successfully in space, were mounted on plinths around the back wall of the space. Functioning as liquid lenses, they channelled light towards the performance space. Before the performers entered the temple, the scrying surface of the black mirror refracted the multiple light sources in the dome and generated symbols and patterns that reconfigured the ambience of the theatre. Movement provoked by spontaneous but minimum disturbances of air, heat and light entangled with dark ground protocell films, which squirmed over the surface of the water, while the fish cast shadows on to the back wall and cut rainbows into the air. As the performers warmed up at the side of the scrying surface, the 


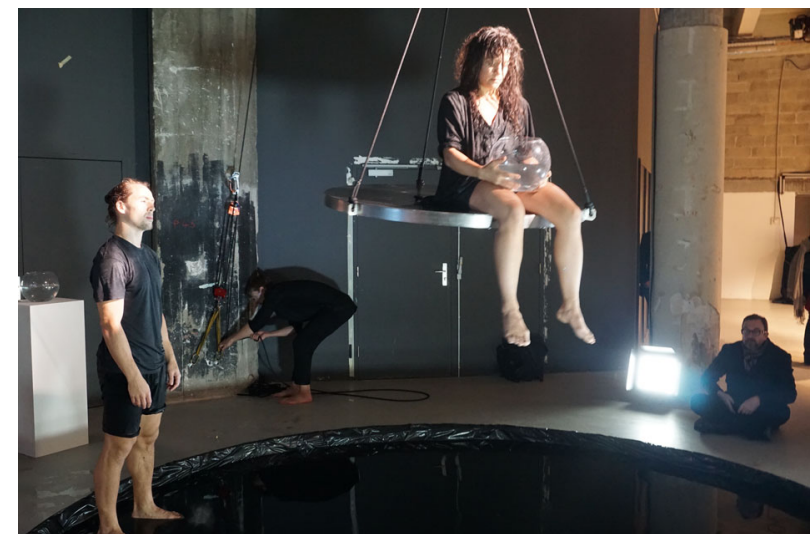

Fig. 1 The Temptations of the Nonlinear Ladder, Palais de Tokyo, Paris, audience perspective, 2016. Reproduced with permission of the Experimental Architecture Group; copyright (c) Experimental Architecture Group, all rights reserved.

aluminium platform was raised by the pulley system. A vertical column and depthless virtual well simultaneously appeared, which became the scaffolding for the non-linear ladder and site of multiple transformations. This analogue yet virtual structure conferred the space with extra dimensionality where familiar and strange new spaces started to overlap and alter each other. During the spectacle of the non-linear ladder, the artists used the apparatus to make a series of occupancy transitions, as they moved from dry land to water and then to the air. In a series of improvisations, they developed a range of bodily movements and spatial configurations that transitioned between the different media. Moving over the black mirror surface, the alternatively configuring bodies produced ripples that collided with each other. Some became stable interference patterns, others chaotic fields and many cancelled each other out. Covered with a reflective film of water, the agitating bodies quickly merged with the images and started to dissolve into the kaleidoscopic surfaces. Droplets, foam, light, sweat, fish, hair, eyes, skin cells, cloth and oils blended with and separated from each other in a shimmering semi-permeable space of multiple transformations-the embodiment of monstering. As typical of non-linear systems, the outputs are not directly proportional to the inputs and exceed our capacity to solve the relationship through classical approaches. It is in these sites that magic is produced, events that are not reducible to simple explanations. And even when observed, they are not demystified through narrative, but raise ethical, philosophical, existential, environmental, technical and cultural questions that create the conditions for a radical identity explosion. Audiences follow the transformations of the circus artists that tread the uncertain pathway towards ascension and another state of being. Performance, site, materials and structures are inseparable during these transitions and become the entangled apparatuses for the synthesis of wonder (Figs 1 and 2).

\section{Making Monsters}

The Making Monsters workshop took place in January 2018 at the University of the Underground, Amsterdam. We invited students in the Masters programme Design of Experiences to develop a range of 'monster' prototypes through different techniques that included creative writing, surrealist drawing, design and performance. Each participant developed critical perspectives on the framing of monsters and their allegorical potential. The first exercise invited students to draw monsters through the surrealist practice of the Exquisite Corpse. The structure of the exercise presumes an implicit order based on a standard human body

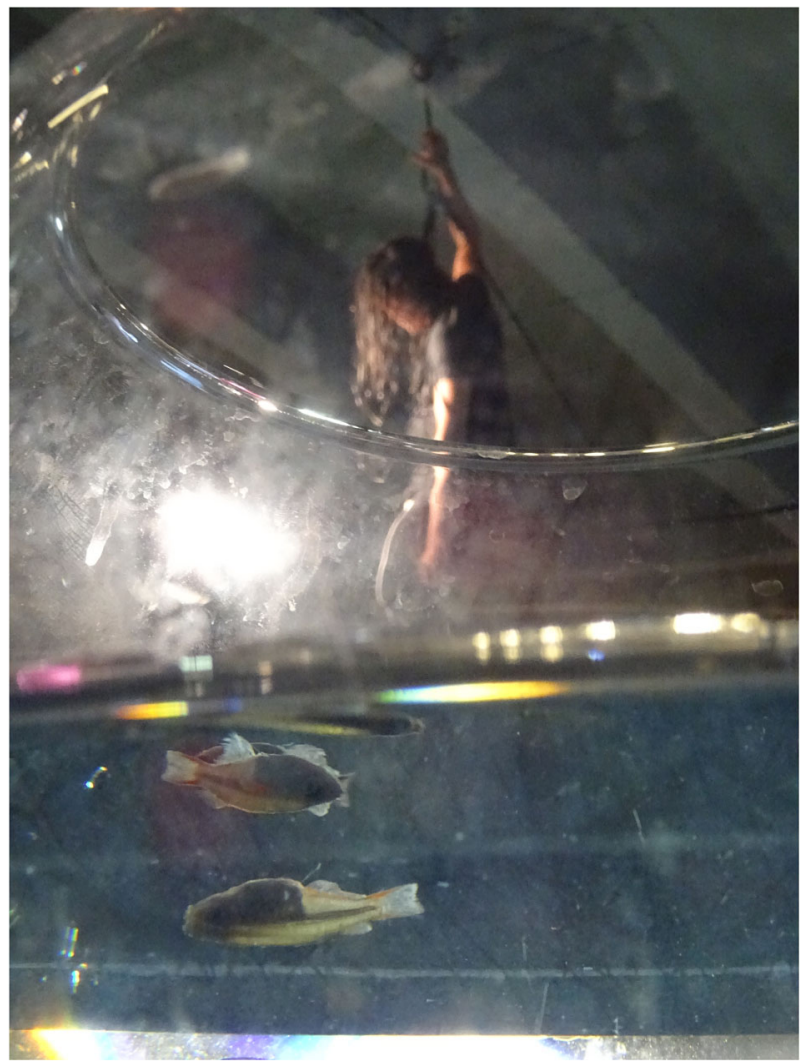

Fig. 2 The Temptations of the Nonlinear Ladder, Palais de Tokyo, Paris, nonhuman perspective, 2016. Reproduced with permission of the Experimental Architecture Group; copyright (c) Experimental Architecture Group, all rights reserved.

(typically, a sequence of body parts, starting from the head downwards, and with an appropriate number of parts). Here, this normative structure was what the monster began to undermine and unravel, with students moving parts (eyes, nipples, mouths, feet, etc.) to unexpected segments, or testing unwieldy adjacencies and repetitions. The resulting monsters always necessitated the non-monster (the ideal body worthy of taxonomic nomenclature) as baseline, limit and ghost-their provocation being only as loud as the distance from the latter allowed. However, a limitless spectrum of combinatorial possibilities could be imagined and drawn. Another round of drawings asked students to represent the objects in the studio, assembling them to create imaginary (monstrous) cities. In this case, assumptions pertaining to the normal layers of a city (skyscrapers, plazas and underground tunnels) were not as pronounced. What students responded to was the violation of a system of appropriate scales and proportional relationships, a deviation in the natural interaction between human bodies and the built environment-from the plastic bottle held in the hand to that same bottle rising high into the city's skyline. Here, monstering was to imagine not only playful new spaces, but also new sets of affordances and, by extension, new bodies. What does it mean to inhabit for the nonstandard organs, movements and perceptual apparatuses of a monster? And how might we design for such a body, one that is always situated and can never be fixed, detached from a milieu, or paraphrased? Further experiments began to test these questions at 1:1 scale, in the studio. In groups, students began to experiment with assemblages of discarded and unused items, used as apparatuses, bodily extensions, vehicles and performance stages. The emerging monsters seamlessly combined human and nonhuman parts, defying the anthropocentric presumption of the former's 


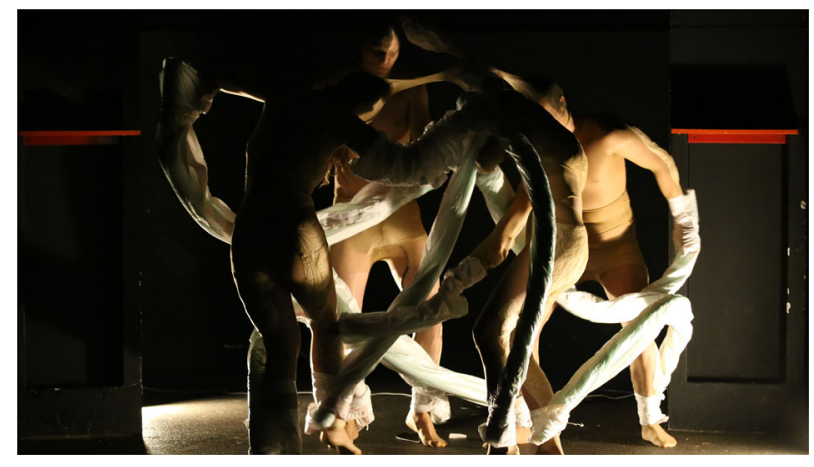

Fig. 3 Making Monsters, De Marktkantine, Amsterdam, interconnected bodies, 2016. Reproduced with permission of the Experimental Architecture Group; copyright (c) Experimental Architecture Group, all rights reserved.

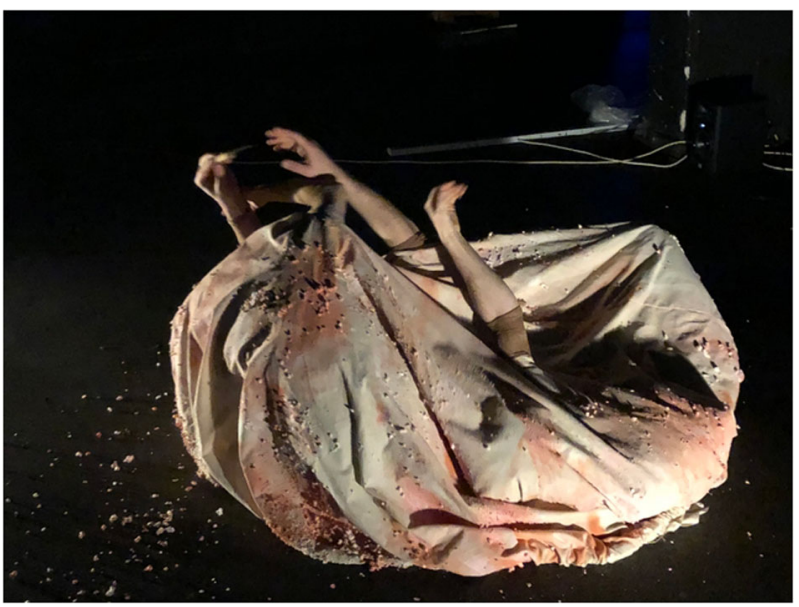

Fig. 4 Making Monsters, De Marktkantine, Amsterdam, bodies-as-one, 2016. Reproduced with permission of the Experimental Architecture Group; copyright (c) Experimental Architecture Group, all rights reserved.

taxonomic priority and ontological superiority, but also questioning the integrity of the unified monster-a whole composed of parts that hardly fit, of parts with no name squirming below the surface; of bodies re-learning how to move and interact, or how to act together as limbs in a larger (collective and hybrid) organism. Assessments were based on a final performance whereby the cultural, social and ethical importance of monsters was given a unique life through the participants' own bodies. Through this immersive experience, peace could be made with these monsters through ongoing negotiations, which were also a measure of an enchanted world-capable of producing unexpected, unknown and uncontrollable aspects of reality shaped by an ethics of difference (Armstrong, 2019, p. 61-62; (Figs 3 and 4)).

\section{Monsters in Utopia}

The Monsters in Utopia installation was a commission for SelfBuild Utopias (Northern Stage, Newcastle, as part of The Great Exhibition of the North, July 2018). We transformed Stage 3 of the Northern Stage, Newcastle, into a 'living' building. Discarded bicycle parts-wheels, gears, inner tubes-inserted into elastic polyurethane tubes formed the structure and guts of the system, stretching the fabric into unfamiliar assemblages. Entering through the rear of the building, visitors were drawn through the assemblage of spaces, reflections and shadows cast by these entrails by a sound installation that evoked the past, present and future of the city through a dense spatialized narrative of spoken

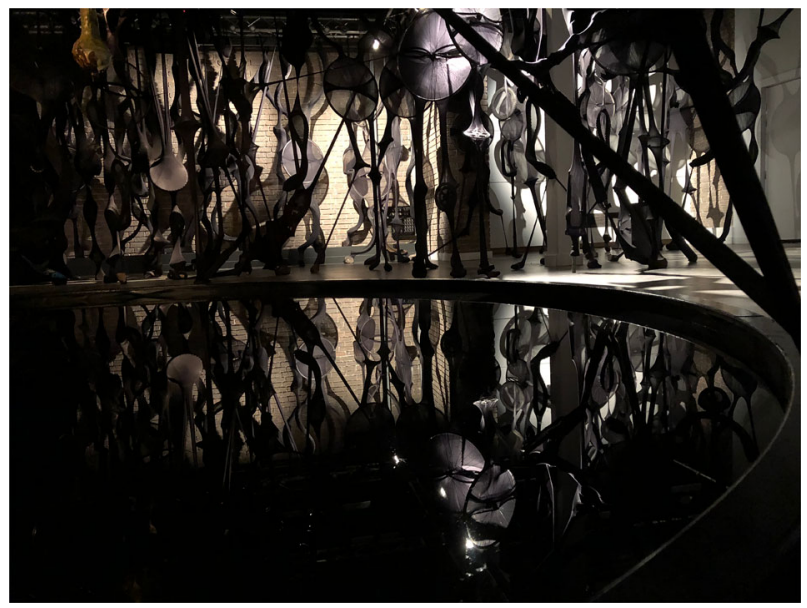

Fig. 5 Monsters in Utopia, Stage 3, Northern Stage, Newcastle-uponTyne, 2018. Reproduced with permission of the Experimental Architecture Group; copyright (c) Experimental Architecture Group, all rights reserved.

word, field recordings and synthesis from six overhead speakers in the main theatre and a series of wall speakers in the surrounding corridors. At the centre of the temple-like space was a reflecting pool-a black mirror that amplified the sinewy surroundings. The strange black organs suspended in the space were multiplied vertically by the reflections on the surface of the water, and at times, following the pulsating rhythm of top-down lights, the space was extended horizontally by the shadows they cast on the walls which, also black, were barely distinguishable from the structures themselves. At times chaotic, at other times meditative, the space resembled an artificial forest-dark, mysterious and unknown, comprising monstrous alliances between metals, textiles, liquid and a constantly mutating ambiance of sonic eventsand yet parts were at times recognisable or, for a moment, nameable, like the eyes, wings or nails of a monster. Its polyphonic voices oscillated imperceptibly between human and nonhuman sounds, field recordings juxtaposed with synthesis-at once seductively coaxing, alienated and disturbing. Monstering here was explored as the perturbation of a baseline, of a habit, of a familiar tool; as the exaptive diversion of organs towards new uses (Ferracina, 2019). Visitors wandered like Jonah within the belly of an unseen creature. Never hearing nor seeing the same combinations, they were peristaltically propelled through the space, eventually exiting into the light of a stairwell and then burped out into the bright daylight of a July morning or afternoon. Assimilated within the 'monster', visitors experienced its multiple identities and histories, echoing the deep biological process of symbiogenesis that was championed by Lynn Margulis (Margulis and Sagan, 1997), where through the 'partial digestions' of creatures (Haraway, 2015) the world 'gave birth to monsters in which one organism engulfed others or joined immoderate liaisons, forming nucleated cells and multicellular organisms called eukaryotes. Ever since we have muddled along in our mixes and messes. All eukaryotic life is monstrous.' (Tsing et al., 2017, M5; (Figs 5 and 6)).

\section{Learning from Landscape: Forging Folklore, Tallinn Tales}

The Learning from Landscape: Forging Folklore, Tallinn Tales workshop was held by the Experimental Architecture Group in August 2018 at the Tallinn Technical University, Estonia. We invited students to a series of 'living' landscapes situated around Tallinn and to re-tell the histories (and re-invoke the character) of these sites as active agents instead of backgrounds to human activity. Highlighting the role of landscape in shaping the way we 


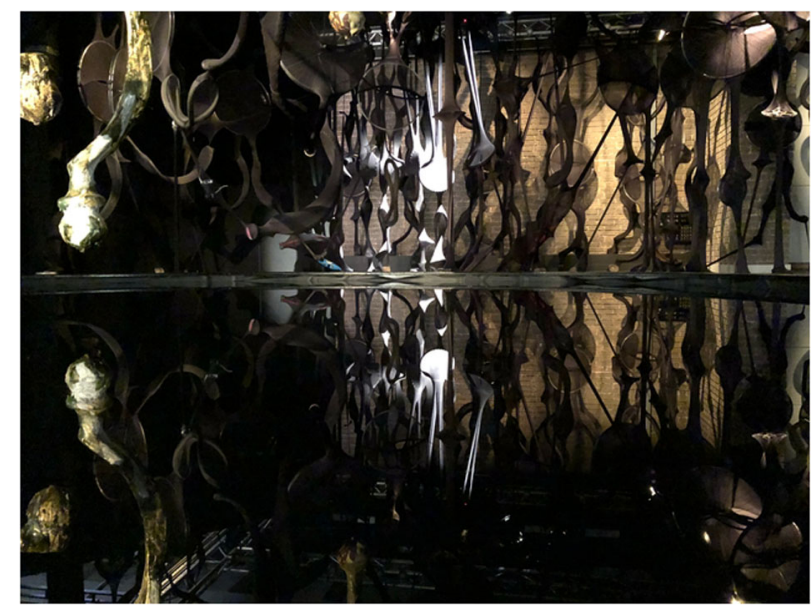

Fig. 6 Monsters in Utopia, Stage 3, Northern Stage, Newcastle-uponTyne, installation viewpoint II, 2018. Reproduced with permission of the Experimental Architecture Group; copyright (c) Experimental Architecture Group, all rights reserved.

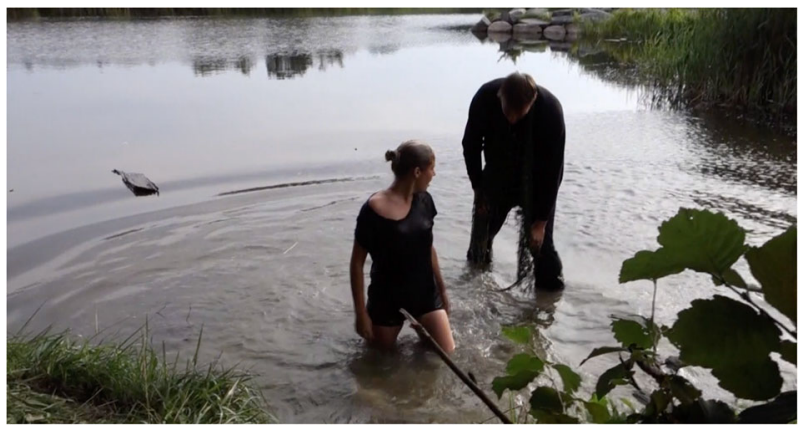

Fig. 7 Learning from Landscape: Forging Folklore, Tallinn Tales, student installation I, 2018. Reproduced with permission of the Experimental Architecture Group; copyright (c) Experimental Architecture Group, all rights reserved.

dwell, natural environments become monstrous beings that act through their assemblages: wild flowers, mists, rivers, sunbeams, a busy beetle, gardens, cities, graffiti, spilt remains of a Friday evening takeaway on the pavement, guano, layers of pollution on brickwork, leftover picnics, the volatile perfumes of late summer flowers, wings flapping in branches thick with leaves, distant traffic jams, plane trails, the spider's patient repair of threads on its web, thunder, burnt plastic wrappers, a runaway balloon, an unexplained blade. Non-human and environmental agents are trivialised and value-managed out of urban and rural spaces. Their vibrancy is muted, or reduced to the pure narratives and functions upon which human life is modelled: to walks in the park, well-being and the ambient rustling of leaves. Drawing from a selection of Estonian folk tales that foreground these landscapes as active participants in the course of human events, the work displaced the tame familiarity and domestication of the world. No longer passive, the spaces around us actively 'came alive' in the student's work-as the uncertain and unruly protagonists of each story (Figs 7 and 8).

\section{From Victoria Tunnel to Quantum Tunnelling}

The From Victoria Tunnel to Quantum Tunnelling performance, for the Being Human Festival was held at the Victoria Tunnel, Newcastle on 17th November 2018, as a collaboration between the Experimental Architecture Group, The Ouseburn Trust and

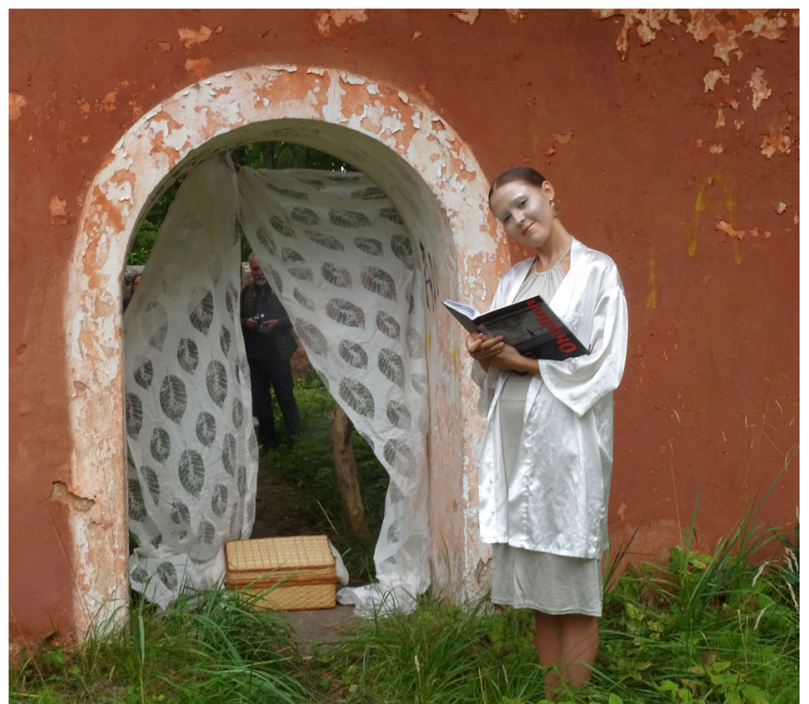

Fig. 8 Learning from Landscape: Forging Folklore, Tallinn Tales, student installation II, 2018. Reproduced with permission of the Experimental Architecture Group; copyright (c) Experimental Architecture Group, all rights reserved.

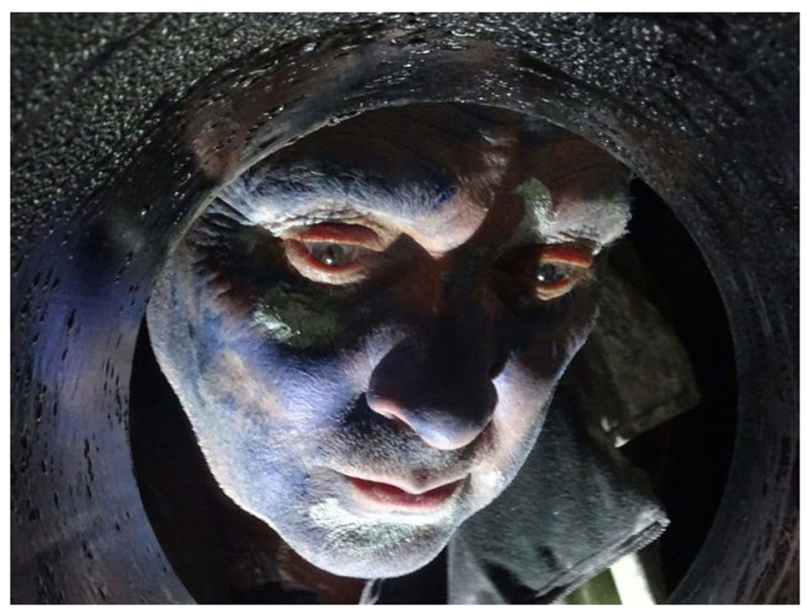

Fig. 9 From Victoria Tunnel to Quantum Tunnelling, for the Being Human Festival, Newcastle-upon-Tyne, 2018. Reproduced with permission of the Experimental Architecture Group; copyright (c) Experimental Architecture Group, all rights reserved.

Culture Lab. Greeted by the 'undead', the audience was accompanied into part of a disused subterranean coal wagonway that runs under the city of Newcastle from the Town Moor to the River Tyne, and invited to consider what it means to live in an abandoned architectural infrastructure that is nonetheless 'alive'. As the visitors explored the space, a narrative performed by the collaborators unfolded around them involving mirrors, chemicals, incantation and sound art. Engaging the darkness, wetness and historical traces of the tunnel such as old light fittings, the underside of Hadrian's Wall and blast barriers, specific events in the tunnel were precipitated, referencing the perambulatory spectacles of Medieval drama, Commedia dell'arte or carnival. This shared journey of strange encounters formed the premise for the installation that took the form of a 'metabolising' space, where visitors were led ever deeper into the tunnel's dripping darkness by their undead guides, ultimately witnessing the structure itself giving birth to new monsters (Figs 9 and 10). 


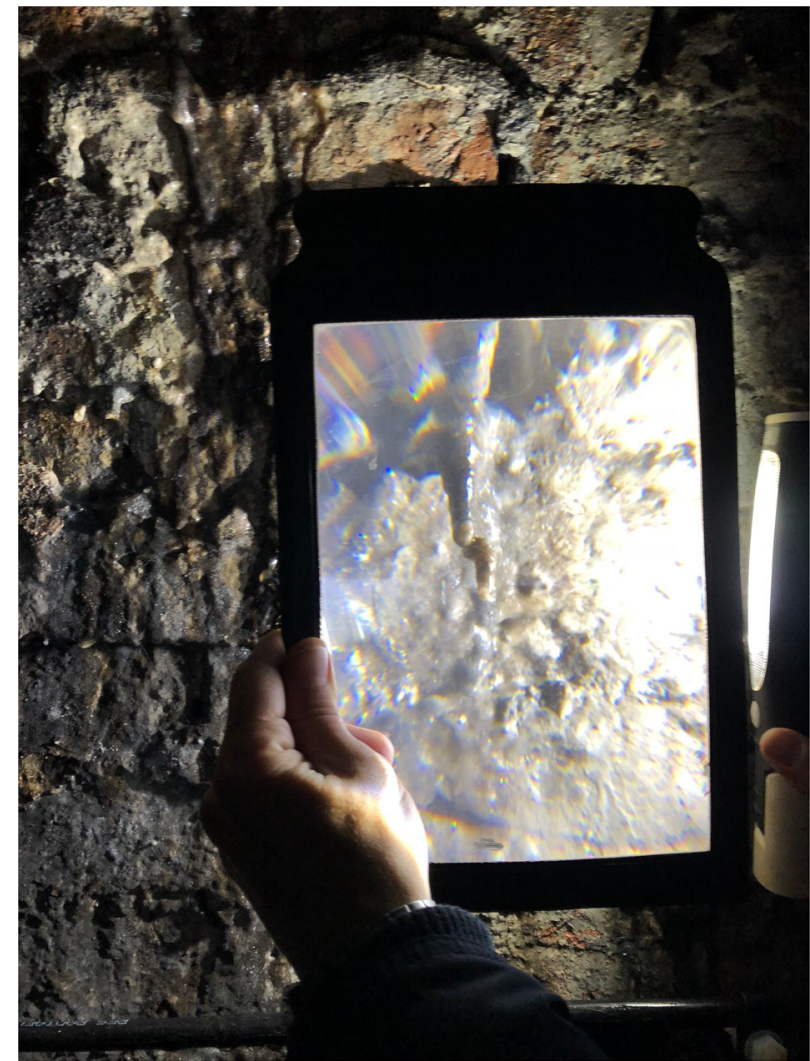

Fig. 10 From Victoria Tunnel to Quantum Tunnelling, for the Being Human Festival, Newcastle-upon-Tyne, audience perspective II, 2018.

Reproduced with permission of the Experimental Architecture Group; copyright (c) Experimental Architecture Group, all rights reserved.

\section{Trace Hall}

The Trace Hall installation for the Cyborg Garden, Matadero, Madrid took the form of a narrow walkway with three steps leading into and out of its empty interior. Cladded by two kinds of reflective surfaces, a dark mirror without, and a silvered mirror within, the structure confused the limits between interior and exterior spaces. As each visitor walked into the lightemitting diode spotlit space, they were immersed in liquid soundscapes that combined natural and artificial flows, water and synthesised energies, recorded resonances and computational models of fluids, scanned and sonified. Two voices, male and female recited by turns a villanelle composed by Rolf Hughes, which draws on the circularity of life and the cycles of growth and decay facilitated by microbes. Instinctively trying to retain their balance, visitors touched the side walls and walked over the mirrored floor of the hall, leaving visible finger and foot traces behind. Here, the everyday presence of people revealed the invisible realm of microbes at the human scale, which was further highlighted by the hall of mirrors. A work in progress, Trace Hall was a model for a structure to house further developments arising from our research into living architecture, specifically the monstering activities of microbial metabolisms. Imagined as a mobile structure, it will one day host an internal public urinal system, hand basin, microbial fuel cell arrays, digital screens, lights and charging sockets to create a whole user experience that transforms liquid human waste into useable amounts of electricity, cleaned water and biomolecules. The work engages a choreography of human and nonhuman agents, whose relations are confused through the multiple active surfaces that reveal the very intersections between people and their microbiomes

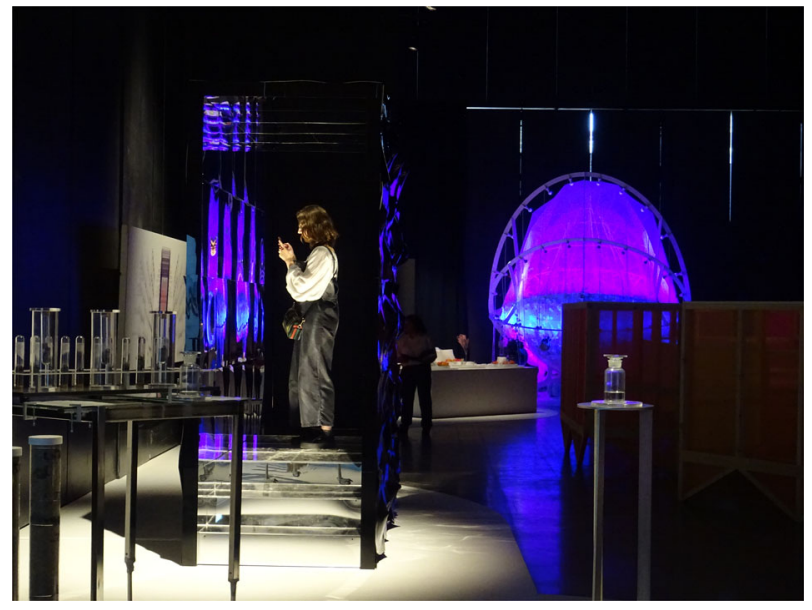

Fig. 11 Trace Hall, for the Cyborg Garden, Matadero, Madrid, installation, photograph courtesy of EAG, 2019. Reproduced with permission of the Experimental Architecture Group; copyright (c) Experimental Architecture Group, all rights reserved.

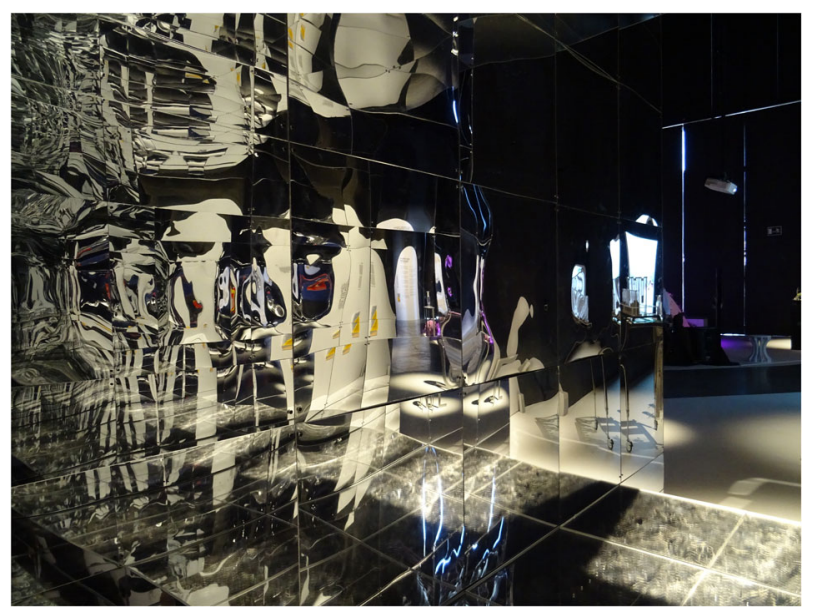

Fig. 12 Trace Hall, for the Cyborg Garden, Matadero, Madrid, reflections, photograph courtesy of EAG, 2019. Reproduced with permission of the Experimental Architecture Group; copyright (c) Experimental Architecture Group, all rights reserved.

through the human traces on the shiny surfaces of the installation, which subtly disclose our interdependencies, making us aware of the invisible realm that we inhabit - the Trace Hall of our life. Mirror, mirror what do you see? I see our microbial reflections (Figs 11 and 12).

\section{Summary}

Monstering is a mutable toolset that enables us to design and innovate for a more-than-human realm. Through defamiliarization, proximity and convergence, our ability to think, practice and inhabit spaces exceeds familiar tropes, formats and protocols, charting new design languages that are structurally profane, transversal, unscripted and collaborative. Departing from the conventions of the archetypal design studio environment, and from the cosmetic impetus (from the Greek kosmos, order) of orthodox design practice, monstering registers events, values and relationships between humans and nonhumans (and, more generally, across taxa) in order to construct generic multiples and stitch together boundaries and territories, tracing new 
cartographies. Here, unfamiliarity is loaded with ethical dilemmas. Monstering's range of atypical approaches challenges our habits, values and preferences. For example, adopting microbiological science as a lens and methodology for design thinking -attributing to micro-ontologies the capacity to set behaviour and performance criteria that can produce alternatives to known typologies-allows other modes of thought, (nonhuman) values and enactments of care to be considered alongside human concerns. Such methods-which are always on the move, uncertain, and redefining 'otherness'-are necessary for bringing to functionality an ecological era of multi-species relations forged by many acts of reciprocity (Wall Kimmerer, 2015) and coconstitution. These may result in the possibility of more liveable-and lively-worlds.

\section{Data availability}

All materials and data are freely available online and can be accessed at: https://livingarchitecture-h2020.eu.

Received: 3 November 2019; Accepted: 28 February 2020;

Published online: 08 April 2020

\section{References}

Armstrong R (2019) Experimental Architecture: Designing the Unknown. Routledge, London

Braidotti R (2006) Transpositions: On Nomadic Ethics. Polity Press, Cambridge

Douglas M (2008) Purity and danger: an analysis of concept of pollution and taboo. Routledge, London and New York, NY

Ferracina S (2019) Exaptive design: radical co-authorship as method. In: Armstrong R (ed) Experimental architecture: designing the unknown. Routledge, London, pp. 121-143

Haraway D (2015) Anthropocene, capitalocene, plantationocene, chthulucene: making kin. Environ Humanities 6:159-165

Linnaeus C (1735) Systema naturae. Sistens regna tria natura in classes et Ordines, genera et species redacta, tabulisque æneis illustrata. Editio multo auctior \& emendatior, Leiden

Marguils L, Sagan D (1997) Microcosmos: four billion years of microbial evolution. University of California Press, Berkeley and Los Angeles

Sowerby R (2016) Angels in early medieval England. Oxford University Press, Oxford

Tsing AL, Swanson HA, Gan E, Bubandt N (2017) Arts of living on a damaged planet: ghosts and monsters of the Anthropocene. University of Minnesota Press, Minneapolis

Wall Kimmerer R (2015) Braiding Sweetgrass: Indigenous Wisdom, Scientific Knowledge and the Teachings of Plants. Milkweed Editions, Minneapolis

\section{Acknowledgements}

The Temptations of the Nonlinear Ladder was a collaboration between Rachel Armstrong, Professor of Experimental Architecture, Newcastle University; Rolf Hughes, Professor of Artistic Research, Stockholm University of the Arts; Olle Sandberg, Director, Cirkör LAB and circus artists Methinee Wongtrakoon (contortionist) and Alexander Dam (acrobat), with technical rigging by Joel Jedström. Making Monsters was an Experimental Architecture Group collaboration between Rachel Armstrong, Andrew Ballantyne, Simone Ferracina and Rolf Hughes with the University of the Underground. Monsters in Utopia was an Experimental Architecture Group collaboration between Rachel Armstrong, Simone Ferracina, Rolf Hughes, Pierangelo Scravaglieri, and sound artists John Bowers and Tim Shaw from Culture Lab, Newcastle University. Learning from Landscape: Forging Folklore, Tallinn Tales workshop was led by the Experimental Architecture Group, Rachel Armstrong, Simone Ferracina, and Rolf Hughes in collaboration with Kristi Grišakov. From Victoria Tunnel to Quantum Tunnelling was a collaboration between Rachel Armstrong, Rolf Hughes, Pierangelo Scravaglieri, John Bowers, Tim Shaw, Simone Ferracina, Clive Goodwin and Kelly Thompson. https://beinghumanfestival.org/event/romvictoria-tunnel-to-quantum-tunnelling/ Trace Hall was an installation by the Experimental Architecture Group (Rachel Armstrong, Rolf Hughes, Pierangelo Scravaglieri), John Bowers and Tim Shaw (Digital Cultures Research Group, Culture Lab and Fine Art), with Ioannis Ieropoulos from the University of the West of England, as part of the Cyborg Garden exhibition for the Eco-Visionaries international exhibition project Art for a Planet in a State of Emergency.

\section{Competing interests}

The authors declare no competing interests.

\section{Additional information}

Correspondence and requests for materials should be addressed to R.A.

Reprints and permission information is available at http://www.nature.com/reprints Publisher's note Springer Nature remains neutral with regard to jurisdictional claims in published maps and institutional affiliations.

\begin{abstract}
Open Access This article is licensed under a Creative Commons Attribution 4.0 International License, which permits use, sharing adaptation, distribution and reproduction in any medium or format, as long as you give appropriate credit to the original author(s) and the source, provide a link to the Creative Commons license, and indicate if changes were made. The images or other third party material in this article are included in the article's Creative Commons license, unless indicated otherwise in a credit line to the material. If material is not included in the article's Creative Commons license and your intended use is not permitted by statutory regulation or exceeds the permitted use, you will need to obtain permission directly from the copyright holder. To view a copy of this license, visit http://creativecommons.org/ licenses/by/4.0/
\end{abstract}

(C) The Author(s) 2020 